\title{
Ecophysiology of antioxidants in poultry diet
}

\author{
Hiyam N. Maty \\ Department of Physiology, Biochemistry and Pharmacology, College of Veterinary Medicine, University \\ of Mosul, Iraq. \\ *Corresponding Author, Hiyam N. Maty, E-Mail: hemyatem@yahoo.com \\ ORCID: https://orchid.org/0000-0003-1792-5192
}

\begin{abstract}
This review was intended to elucidate the role of antioxidants in poultry feed formula on bird's ecophysiology. Naturally, many compounds have antioxidant features, including fat and water-soluble compounds, which can either be synthesized by the body or supplemented with a diet. The additive of antioxidants on poultry fodder is usually utilized in order to elevate the steadiness of feed. Nevertheless, some antioxidants are believed to have biological consequences in vivo. Oxidative stress clues to biological destruction, which in turn can disturb growth and production in farmstead animals. These Stressful factors are created reactive oxygen species. Therefore, the natural and synthetic antioxidants that add to animal feed are important to diminish the free radicals that are thought to unfavorably on growth, immune status, elevated lipid rancidity, and poor quality of meat. Supplementation of balanced feed with many ingredients including natural and synthetic antioxidants will improve the bird's performance and other physiological aspects by reducing the significant effects of free radicals. In conclusion, feed additive including antioxidants integrated with feed formula is beneficial and valuable to exclude and prevent the destructive effects of reactive oxygen species on physiological aspects of vital organs, maintenance of homeostasis, Repair and removal of harmed particles, activation of apoptosis and finally limit of mutagenesis.
\end{abstract}

Original Article:

DOI:https://dx.doi.org/10.21608/javs.2 $\underline{021.79441 .1084}$

Received :06 June, 2021. Accepted :08 July, 2021.

Published in July, 2021.

This is an open access article under the term of the Creative Commons Attribution 4.0 (CC. BY) International License. To view a copy of this license, visit:

http://creativecommons.org/licenses/by/4.0/

J. Appl. Vet. Sci., 6(3 ): 54 -59.

Keywords: Ecophysiology, mutagenesis, physiological antioxidant, poultry diet.

\section{INTRODUCTION}

No definition clarity of the term "stress" therefore, has several clarifications of stress. "Everybody knows what stress is and nobody knows what it is" and "a nonspecific response of the body to any demand made upon it" (Selye, 1973). Also, (Moberg and Mench, 2000) describe stress as a "threat to homeostasis" Vitally though, an incentive that creates considered positive stimuli like exercise, arousal, and excitement etc....can trigger the hypothalamus-pituitary-adrenal axis ( HPA-axis). And therefore construed as stress and thus included in the definitions mentioned above. While the thought debated by Koolhaas et al., (2011) to understand stress and riposte is considered normal physiological processes and not regarded as stress. Physiological response to stress triggers four cascades of reactions as mentioned by Love et al., (2013) firstly activate the autonomic nervous system, endocrine system, immune system and finally depend on behavioral effects. In mature chickens, when elevation the cortisol which affects alterations of many physiological parameters, like diminishing in body weight and relative of organ masses, the elevation of blood glucose, fat metabolite, and heterophil/lymphocyte ratio (stress index) (Shini $\boldsymbol{e t}$ al., 2009).

But in Japanese Quail, the physiological response to raises the cortisol has been unsuccessful in showing any later effects; therefore, we noticed the quail reached puberty earlier than other birds with a high response (Marasco et al. 2012). Greatest biologically- pertinent are free radicals which originated from oxygen and nitrogen atoms have free electrons (unpaired electrons) in outer orbit, So-known as reactive oxygen species (ROS) and reactive nitrogen species (RNS). In normal circumstances, these two molecules have a vital role in the body but 


\section{Hiyam N. Maty}

can acquire the reactive capacity to become harmful to vital biological molecules (Surai, 2002a).

In poultry, the physiology of the gastrointestinal tract (GIT) has great ability to create reactive oxygen species (ROS) and reactive nitrogen species (RNS) that are generated by epithelial cells, either one from oxygen metabolism or by microbiota, to adjust gut healthiness. So, the possibility of oxidative stress is high by producing free radicals at higher than levels of antioxidants. Therefore, supplementation a diet has antioxidant properties to scavenger ROS and helpful in alleviating oxidative stress in the poultry gut (Mishra and Jha, 2019).

In addition, the active oxygen species are also created from mitochondria and macrophages; it participate a vital role in damaging major biological particles comprising proteins, lipids, DNA, and RNA molecules that lead to generating stress reaction and activation groups of genes known as vintages that affect to redox equilibrium, stress resistance and adjustment suitable health, elevated immunity productive and reproductive performing in avian ( Surai et al., 2019).

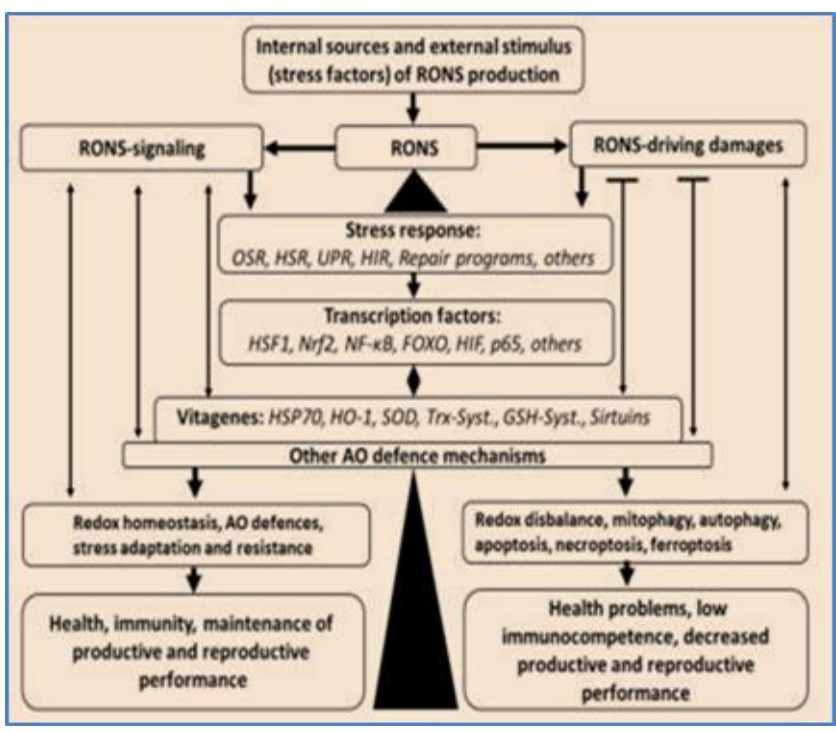

Fig. 1: The antioxidant defense system in poultry (Surai et al., 2019)

The first system can combat against free radical production is digestive system as a general and the intestinal cells as a special, because the epithelial cells are unceasingly exposed to free radicals that physiological create from oxygen metabolism which are hydroxyl free radical, superoxide, and the hydrogen peroxide $(\mathrm{H} 2 \mathrm{O} 2)$, secondly endogenous antioxidant considered as second line to prevent peroxidation of lipids, nitration of protein, destruction of DNA and apoptosis which are glutathione peroxidase, superoxide dismutase, and catalase (Estevez,2015). Superoxide dismutase either SOD1 or SOD2 can catalyzes to convert the superoxide anion $(\mathrm{O}-2)$ to hydrogen peroxide $(\mathrm{H} 2 \mathrm{O} 2)$, that cause disintegrated into water and oxygen molecules by enzyme known as catalase, But glutathione peroxidase (GPX) lessens lipid oxidation (Fukai et al., 2011). Also the absorption of nutrient impairment when elevated nitric oxide radical (NO•) which are production from arginine and citrulline that cause destructions of intestinal mucous. (Sklyarov et al., 2011). Continuous exposure to stress losses the mucosa of intestine ability to digestion of nutrient and make inefficient absorption this is adversely redirected in adjustment normal growth of the animals (Yara , 2013)

Poultry industry, in the last decades has created marvelous advancement of quantity and property of chicken meat, production and quality of egg. However, it has associated with a variety of stresses involving physiological stress that affected by environmental factors, technological, diet, and the biological environment of the bird (Surai and Fisinin, 2016). Therefore, tremendous production of reactive oxygen species are public problems in poultry industry. Natural and synthetic antioxidants must be added to poultry diet.

living creatures have a specific antioxidant protective defensive, procedure to cope with reactive oxygen species which are steadily generated in the organism cells are termed generaly "antioxidant system" (Surai, 2002a). naturally, there are thousands of composites having antioxidant features to fit counteract with free radicals, include fat-soluble vitamin and water-soluble vitamin, or synthesized endogenously such as ascorbic acid, glutathione, or maybe supplied via diet such as minerals, vitamin E, carotenoids. Additionally, the generation of mineralrelated antioxidant enzymes can deal with reactive oxygen but at the same time need the feed-derived minerals to do so. (example) the selenium in the form of selenocysteine is an important part of the enzyme family named glutathione peroxidases (GSH-Px) and thioredoxin reductases (TR), dissimilarly depletion of those minerals which can result in oxidative stress and destroyed the biological molecules and membranes (Surai et al., 2019). A gauge of the antioxidant of the body is also named equilibrium with oxidative materials and can be divided in natural antioxidants considered as an essential feature in poultry food.

\section{Natural antioxidants:}

Natural antioxidants in poultry feed are safer, inexpensive and can prevent oxidative responses in diet during storage also don't cause metabolic disorders in poultry body, are a good substitute to synthetic ones. The Enzymes with antioxidant activity are produced in the body and need co-factors for its stimulation; examples for these antioxidants include selenium, glutathione peroxidases (GSH-Px) and thioredoxin reductase (TR). Many Co factors as Zinc, copper and 


\section{Ecophysiology of antioxidants in poultry diet}

manganese are form a basic portions for superoxide dismutases (SOD); while iron is a crucial element for catalase (an antioxidant enzymes). Balanced diet with sufficient amount of antioxidants like vitamin $\mathrm{E}$ is useful. Instead of that, an oxidative stress show remarkable elevation of free radicals especially with low supplemented feed additives with antioxidants. Thus undesirable effects will include injury and impairment of vital tissues. Therefore the supplement of natural antioxidants, especially vitamin $\mathrm{E}$ and selenium will help the nutritionists in the formulating of feed formula to challenge the deficient amount of antioxidant in feed and determined the feed additive quantity that is needed and cost - effectively validated (Surai, 2002b).

There are three level of defending system with antioxidants, the 1st one is not adequate to provide a full protection from free radicals creation and lipid peroxidation, and the 2 nd level act to prevent and restrict the series of free radical effects and this level is unable to protect the biological products and some lipids, proteins, carbohydrates and DNA. Hence the 3rd level of defending is depending on the action of particular enzymes such as (lipase, proteases, and repairing enzymes of DNA) which eliminate injured biological molecules (Surai, 2002a).

\section{Available natural antioxidants in poultry feed formula:}

In general there are many natural compounds act as antioxidant that available and usually formulated with feed of poultry. Therefore this poultry diet comprises from a variety of several compounds that influence antioxidant actions (Surai and Dvorska, 2002). Hence the followings compounds list are represent more popular antioxidants in poultry feed

\section{Vitamin E:}

It plays crucial effects in several biochemical and physiological activities, including antioxidant processes (Litta et al., 2014) . Many of studies showed that Vitamin E had beneficial effects in poultry by improving the oxidative stability of body tissues, growth performance and meat quality (Niu et al ., 2018). Current data revealed that arise in supplementation of vitamin $\mathrm{E}$ is beneficial as antistressful compound for poultry (Surai and Dvorska, 2002b). Vitamin E performs its function by blocking lipid peroxidation with scavenging and diminishes the action of free radicals

\section{Vitamin C:}

It acts mainly as anti-stress agent. It is proposed that the producing ability of birds may become inefficient under high thermal conditions, and the poultry performance is improved after exposure to high temperature conditions with Vitamin C supplement (Attia et al., 2011), therefore the antioxidant outcome of vitamin $\mathrm{C}$ might incompletely impede with oxidative protein denaturation and would enhance the feed and nutrients digestibility. In addition Vitamin $\mathrm{C}$ has a significant action in biosynthesis of corticosterone which is that improve of body function to overcome stressful condition (Ahmadu et al., 2016)

\section{Carotenoids:}

Attention for Appling of carotenoids as feed additives has been grown obviously due to their biological features. Carotenoids decrease the oxidative stress in pre and post hatching birds by different ways, including diminish of free radicals, and enhancing the antioxidant enzymes activity. Application of carotenoids in poultry diet provides an improvement of poultry health and with high quality products (Nabi $\boldsymbol{e} t$ al., 2020).

\section{Selenium :}

Selenium is available in 2 types: organic form that mainly found in any in feed component with variable concentrations and inorganic form which are usually used as dietary supplements. Selenium contributes in different biochemical and physiological roles as an essential element of a variety principle selenoproteins. A 26 chicken genes encoding for distinct selenocysteine (SeCys) -containing proteins have been recognized .Remarkably, more than half of selenoproteins are included as antioxidant effects and supporting the redox equilibrium of cells (Zhao et al., 2017).

\section{Polyphenol:}

They act by protecting the cells from free radicals by the different ways including firstly: impairment of pro oxidant enzymes such as xanthine oxidase, protein kinase $\mathrm{C}$ (PKC) and membraneassociated $\beta$-NADPH oxidase, secondly: activation of an antioxidant enzymes and immediate scavenging of reactive oxygen species ROS (Procházková et al., 2011), thirdly: inhibit hydroxyl radicals $\mathrm{OH}$ synthesis and finally: decrease of $\alpha$-tocopherol radicals and improving the antioxidant action (Lipiński et al., 2017).

\section{Synthetic antioxidants in poultry feed formula:}

During stock pilling of animal diet, we need to stay the regimen of animals freshness as long time as possible, because numerous various processes may take place which modifies their chief natural proprieties. At beginning of all, lipids endure peroxidation, because the catalytic reaction of atmospheric oxygen leads to the continuous production of the free radicals and initiates peroxidation (food rancidity) manifests by strange taste, odor, and color as well as reduce the duration of storage the product (Rumsey, 1980). If the antioxidant not enough or absent the unsaturated fatty acids suffered from rancidity by this pathway including firstly the hydrogen is lost from unsaturated fatty acid 


\section{Hiyam N. Maty}

and as resulting of this pathway leads it produces free radicals, then speedily converted to a fatty acid peroxide and finally to hydroperoxide but when present antioxidant lead to provided hydrogen and inhibit peroxidation.



Fig. 2: Lipid peroxidation (Castillo et al., 2013)

Alot's of natural antioxidants, as vitamin $\mathrm{E}, \mathrm{C}$, flavonoids affect for a limited period of preserving time, hence synthetic antioxidants are vastly used. The most popular synthetic antioxidant are BHT (butylated hydroxytoluene), BHA (butylated hydroxyanisole), TBHQ (tertiary-butyl hydroquinone) and EQ (ethoxyquin) (6-ethoxy-1,2-dihydro-2,2,4-trimethylquinoline) (EQ) are the most frequent used especially in processed poultry and fish feed (Antony, 2017).

\section{Ethoxyquin:}

It is widely handled because of its new technologies may drive production costs down and higher antioxidative effect as well as have benefit effect of to protect lipid from peroxidation, also uses to preserved pet food as well as farmed fish or poultry and even human (Baszczyk et al., 2013). Ethoxyquin in a pure forms is a liquid and lightly yellowish in color, but it alterations to brown and polymerize when subjected to oxygen. It is merely soluble in organic solvents (Koning, 2002). EQ has a critical role to safeguard lipids in food against rancidity. Delayed oxidation of vitamins A and E, xanthophylls, carotene, as well as add the ethoxyquin to animals' diet lead to elevate the level of vitamins $\mathrm{A}$ and $\mathrm{E}$ in the plasma higher than three-level was observed as well as allow the levels of vit-A storage in the liver is high.

Therefor, some researchers believed using EQ has high-efficiency than natural antioxidants (Koning, 2002). Recently observe the ability of EQ to react with alkylperoxyl in the presence of oxygen which is also a strong antioxidant (Taimr, 1994). Antimutagenic action of EQ this antioxidant was noted in experimental animals such as hamsters, mice, and rats subjected to cyclophosphamide to produce reactive oxygen species that can cause damage to genetic material. the EQ can modify the effect of cyclophosphamide by decreasing the number of chromosome deviations, micronuclei, and leading to lethal mutations provoked by the anticancer medicine (Ray et al., 2010).

Hernandez et al., (1993) detected influence of EQ on mechanism that generate energy in cells by constraining $\mathrm{Na}+, \mathrm{K}+-\mathrm{ATPase}$ pumping mechanism in renal and liver cells and then, interrelate with the respiratory chain of mitochondria caused in the restraining of oxygen consumption in the mitochondria. There are 9 analogs of EQ intended to compare their antioxidant activity. such as, hydroxyquin was 3.5 times as efficient as EQ, while hydroquin able to contest with EQ as an antioxidant. Hydroquin was previous discovered as an antioxidant in the animal diet in 1997, (Koning, 2002).

\section{Butylated Hydroxyanisole (BHA) and Butylated Hydroxytoluene (BHT):}

To highlight the remainder of the antioxidants that lowering the effect of polyunsaturated fatty acid from endogenous oxidation, including Butylated Hydroxyanisole "BHA", Butylated Hydroxytoluene "BHT", Propyl Gallate "PG" and TertButylhydroquinone "TBHQ" have been usually used in the America and various countries to delay the expansion of rancidity of preserving diet. as well as these artificial antioxidants are professional also it is proportionately inexpensive (Frankel, 2012). The effectiveness of these antioxidants employed two pathways: (BHA) and (BHT) react with peroxly radicals and prevent the development of it; while plentiful other antioxidants such as carotenoids turn off the reactivating singlet state of oxygen and modified it into a triplet state (Frazier , 2010). Electrospinning technology is of magnificent efficiency in food preservation, including production Nano fibers has different surface areas to raising the effectiveness of encapsulation synthetic antioxidant, BHA covered by a gelatinous capsule to act as an antibacterial and antifungal agent (Chadha, 2021).

The aim of the dealing poultry diet with antioxidants is to boost the steadiness of oxidation for a long time ago for a safe nutritional value of poultry meals (Dozier , 2003). Therefor Frankel et al. in 1994 classified antioxidant according their ability to compete with reactive oxygen species to Primary antioxidants, for example vitamin c, (BHT), (BHA), and (TBHQ), are peroxide stabilizers, while second classified of antioxidants lecithins prolong the progression of the beginning oxidation (Frankel et al., 1994) . Dassarma et al., (2018) proved the add BHA and BHT to preserving food formulations may be positive effect for liver cells. 


\section{CONCLUSIONS}

Oxidative stress has an impact and adverse effect in poultry performance, therefore improving the antioxidants effects by supplementation of natural and synthetic antioxidants with poultry feed in balanced formula will help to alleviate the effect of stressful condition, reduction of lipid peroxidation and maintain the productivity trait.

\section{Conflict of interest}

The authors declare that there is no conflict of interest

\section{REFERENCES}

AHMADU S, MOHAMMED AA, BUHARI H. AND AUWAL A., 2016. An overview of vitamin $\mathrm{C}$ as antistress in poultry. Malaysian Journal Veterinary Research. 7. $2: 9-22$.

ANTONY, R., 2017. The Synthetic Antioxidant Ethoxyquin and its Effect on Fish Products. Advanced Food Chemistry.23 Pages

ATTIA Y A, HASSAN RA, TAG EL-DIN A.E. AND ABOU-SHEHEMA B.M., 2011. Effect of ascorbic acid or increasing metabolizable energy level with or without supplementation of some essential amino acids on productive and physiological traits of slow-growing chicks exposed to chronic heat stress. J Anim Physiol Anim Nutr .Dec; 95(6):744-55.

BASZCZYK A, AUGUSTYNIAK A. AND SKOLIMOWSKI J., 2013. Review Article Ethoxyquin: An Antioxidant Used in Animal Feed. International Journal of Food Science .ID 585931, $12 \quad$ pages http://dx.doi.org/10.1155/2013/585931

CASTILLO C, PEREIRA V, ABUELO A, HERNANDEZ J.2013. Effect of Supplementation with Antioxidants on the Quality of Bovine Milk and Meat Production. The Scientific World Journal Volume .Article ID 616098, Page: 8 . doi.org/10.1155/2013/616098

CHADHA S. 2021 . Recent advances in nano-encapsulation technologies for controlled release of biostimulants and antimicrobial agents. Pesticides in Agriculture .Technology and Nutrition. Pages 29-55. https://doi.org/10.1016/B978-0-12-820092-6.00002-1

DASSARMA B NANDI DK, GANGOPADHYAY S. AND SAMANTA S., 2018. Hepatoprotective effect of food preservatives (butylated hydroxyanisole, butylated hydroxytoluene) on carbon tetrachloride-induced hepatotoxicity in rat. Toxicol Rep. 5: 31-37. doi: 10.1016/j.toxrep.2017.12.009

DE KONING AJ., 2002."The antioxidant ethoxyquin and its analogues: a review," International Journal of Food Properties, vol. 5, no. 2, pp. 451-461,.

DOZIER WA, DALE N, DOVE CR.2003. Nutrient composition of feed-grade and pet-food-grade poultry byproduct meal. Journal Applied Poultry Research ;12(4):526-530
ESTEVEZ M., 2015. Oxidative damage to poultry: from farm to fork. Poult Sci. 94:1368-78 .doi: 10.3382/ps/pev094.

FRANKEL EN, HUANG SW, KANNER J, GERMAN JB.1994. Interfacial phenomena in the evaluation of antioxidants: Bulk oils versus emulsions. Journal of Agriculture and Food Chemistry , 42(5):1054-1059.

FRANKEL EN., 2012. Chapter 9 - Antioxidants Lipid Oxidation (Second Edition) .Oily Press Lipid Library Series, 2012, Pages 209-258. https://doi.org/10.1533/9780857097927.209

FRAZIER RA IN ENCYCLOPEDIA OF SEPARATION SCIENCE, 2007. CAPILLARY ELECTROPHORESIS | Food Additives. Pages 1-7. Reference Module in Chemistry, Molecular Sciences and Chemical Engineering. https://doi.org/10.1016/B978-012226770-3/10728-9

FUKAI T. AND USHIO-FUKAI M., 2011. Superoxide dismutases: role in redox signaling,vascular function, and diseases.Antioxid Redox Signal. 15:1583-606. doi: 10.1089/ars.2011.39997.

HERNANDEZ ME, REYESJL, GOMEZ-LOJERO C, SAYAVEDRA MS, AND MELENDEZ E., 1993. "Inhibition of the renal uptake of paminohippurate and tetraethylammonium by the antioxidant ethoxyquin in the rat," Food and Chemical Toxicology, vol. 31, no. 5, pp. 363-367.

KOOLHAAS JM, BARTOLOMUCCI A, BUWALDA B, DE BOER SF, FLÜGGEG, KORTE SM, MEERLO P, MURISON R, OLIVIERB, PALANZA P, RICHTER-LEVIN G, SGOIFO A, STEIMER T, STIEDL O, VAN DIJK G, WÖHR M. AND FUCHS E., 2011. Stress revisited: A critical evaluation of the stress concept. Neuroscience \&amp; Biobehavioral Reviews. 35, 1291-1301. doi: 10.1016/j.neubiorev.2011.02.003.

LIPIŃSKI K, MAZUR M, ANTOSZKIEWICZ Z, AND PURWIN C., 2017. Polyphenols in monogastric nutrition - A review. Annals of Animal Science, 17(1), 41-58. https://doi.org /10.1515/ aoas-2016-0042

LITTA G, CHUNG TK. AND WEBER GM., 2014. Vitamin E: vital for health and performance. Word Poultry 2014. Available from: http://www.worldpoultry.net/Broilers Nutrition-2014 1437326.

LOVE OP, MCGOWAN PO. AND SHERIFF MJ., 2013. Maternal adversity and ecological stressors in natural populations: the role of stress axis programming in individuals, with implications for populations and communities. Maternal adversity and ecological. Funct. Ecol. 27, 81-92. https://doi.org/10.1111/j.13652435.2012.02040.x.

MARASCO V, ROBINSON J, HERZYK P. AND SPENCER KA., 2012. Pre- and post-natal stress in context: effects on the stress physiology in a precocial bird. J. Exp. Biol. 215: 3955-3964; doi: 10.1242/jeb.071423.

MISHRA B. AND JHA R., 2019. Oxidative Stress in the Poultry Gut: Potential Challenges and Interventions. Front Vet Sci. 6: 60. doi: 10.3389/fvets.2019.00060

MOBERG GP., 2000. Biological response to stress: Implications for animal welfare. In: Moberg, G.P. and Mench, J.A., Eds., The Biology of Animal Stress: Basic 
Principle and Implications for Animal Welfare, CABI Publishing, London, 1-21. doi:10.1079/9780851993591.0001

NABI F, ARAIN MA, RAJPUT N, ALAGAWANY M, SOOMRO J, UMER M, SOOMRO F, WANG, YE ZR. ND LIU J., 2020. Health benefits of carotenoids and potential application in poultry industry: A review. Journal of animal physiology and animal nutrition. 104:1809-1818.

NIU ZY, MIN YN. AND LIU FZ., 2018. Dietary vitamin E improves meat quality and antioxidant capacity in broilers by upregulating the expression of antioxidant enzyme genes.2018. Journal of Applied Animal Research. Volume 46, 1:397-401.

PROCHÁZKOVÁ D, BOUŠOVÁ I. AND WILHELMOVÁ N., 2011. Antioxidant and prooxidant properties of flavonoids. Fitoterapia, 82(4), 513-523.https://doi.org/10.1016/ j.fitote. 2011.01.018

RAY S., B. PANDIT, S. D. RAY, S. DAS, AND CHAKRABORTY, S., 2010. "Cyclophosphamide induced lipid peroxidation and changes in cholesterol content: protective role of reduced glutathione," International Journal of PharmTech Research, vol. 2, no. 1, pp. 704-718.

RUMSEY, G.L., 1980. Antioxidants in compounded feeds. Book Chapter 10, Edited by: K.W. Chow. Published by Food and Agriculture Organization of the United Nations, Rome, Italy. https://pubs.er.usgs.gov/publication/95262

SELYE H., 1973. The Evolution of the Stress Concept: The originator of the concept traces its development from the discovery in 1936 of the alarm reaction to modern therapeutic applications of syntoxic and catatoxic hormones. Am. Sci. 61, 692-699.

SHINI S, SHINI A. AND HUFF GR., 2009. Effects of chronic and repeated corticosterone administration in rearing chickens on physiology, the onset of lay and egg productionof hens. Physiol. Behav. 98, 73-77. Huff. Effects of chronic and repeated corticosterone administration in rearing chickens on physiology, the onset of lay and egg production of hens. April 2009Physiology \& Behavior 98(1-2):73-7. DOI: 10.1016/j.physbeh.2009.04.012.

SKLYAROV AY, PANASYUK NB. AND FOMENKO IS., 2011. Role of nitric oxide-synthaseand cyclooxygenase/lipooxygenase systems in development of experimentalulcerative colitis.J Physiol Pharmacol. 62:65-73

SURAI P.F. AND DVORSKA J.E., 2002. Strategies to enhance antioxidant protection and implications for the well-being of companion animals. In: Nutritional Biotechnology in the Feed and Food Industries. Proceedings of Alltech's 18th Annual Symposium, pp.521-534 (T.P.Lyons and K.A. Jacques, editors). Nottingham: Nottingham University Press.

SURAI PF, KOCHISH II, FISININ VI. AND KIDD MT., 2019. Antioxidant Defence Systems and Oxidative Stress in Poultry Biology: An Update. Antioxidants.;8:7. doi: 10.3390/antiox8070235.

SURAI PF. AND FISININ VI., 2016. Vitagenes in poultry production. Part 2. Nutritional and Internal stresses. World's Poult. Sci. J. 72: 761-772. doi: 10.1017 /S0043933916000726.
SURAI PF., 2002a. Natural Antioxidants in Avian Nutrition and Reproduction. Nottingham University Press, Nottingham. First published. Chapt 09-.p65.

SURAI, PF., 2002b. Selenium in poultry nutrition: a new look at an old element. 2. Reproduction, egg and meat quality and practical applications. World's Poultry Science Journal 58: 431-450.

TAIMR L. 1994 "Study of the mechanism of the antioxidant action of ethoxyquin," Angewandte Makromolekulare Chemie, vol. 217, pp. 119128.https://doi.org/10.1002/apmc.1994.052170112

YARA S, LAVOIE JC, BEAULIEU JF, DELVIN E, AMRE D, MARCI V, ET AL., 2013. Iron-ascorbatemediated lipid peroxidation causes epigenetic changes in theantioxidant defense in intestinal epithelial cells: impact on inflammation.PLoSONE. 8:e63456. doi: 10.1371/journal.pone.0063456.

ZHAO L, SUN LH, HUANG JQ, BRIENS M, QI DS, XU SW AND LEI XG., 2017. A novel organic selenium compound exerts unique regulation of selenium speciation, selenogenome, and selenoproteins in broiler chicks. Journal of Nutrition 147: 789-797.

How to cite this article:

Hiyam N. Maty, 2021. Ecophysiology of antioxidants in poultry diet. Journal of Applied Veterinary Sciences, 6 (3): $54-59$.

DOI:https://dx.doi.org/10.21608/javs.2021.79441.1084 